\title{
UMA REFLEXÃO SOBRE UMA MODALIDADE DE EDUCACÃO PARA SENSIBILIZAÇÃO AMBIENTAL
}

\author{
A REFLECTION ON A MODALITY OF EDUCATION FOR ENVIRONMENTAL \\ AWARENESS \\ UMA REFLEXIÓN SOBRE UMA MODALIDAD DE EDUCACIÓN PARA \\ SENSIBILIZACIÓN AMBIENTAL
}

\section{Ari Silva Gobira* \\ arigobira@gmail.com}

Áurea Regina Guimarães Tomasi**

aureagt@gmail.com

REVISTA PEDAGÓGICA

Revista do Programa de Pós-graduação em Educação da Unochapecó | ISSN 1984-1566

Universidade Comunitária da Região de Chapecó | Chapecó-SC, Brasil Como referenciar este artigo: GOBIRA, A. S.; TOMASI, A. R. G. Uma reflexão sobre uma modalidade de educação para sensibilização ambiental. Revista Pedagógica, Chapecó, v. 19, n. 40, p. 216-241, jan./abr. 2017. DOI: http://dx.doi.org/10.22196/rp.v19i40.3751

RESUMO: Diante da complexidade da prática da Educação Ambiental e da diversidade de sujeitos, das mais diversas áreas do conhecimento, que atuam nesse campo, é preciso levantar alguns questionamentos sobre o papel desses educadores e quais são as possibilidades e as colaborações que eles podem proporcionar para o desenvolvimento local dos territórios onde estas são desenvolvidas. Portanto, o objetivo deste trabalho foi refletir sobre as ações de Educação Ambiental, de modo que possibilite compreender o sentido dessa modalidade de educação, uma vez que não é somente uma atividade do educador formal. O artigo se apoia em uma revisão bibliográfica sobre a temática e a formação de educadores. Assim, esta reflexão parte do seu processo histórico, passando pelas modalidades de Educação Ambiental e finalmente chegando ao processo de formação dos docentes e na forma com as ações são desenvolvidas. Ao longo do texto, buscou-se levantar algumas considerações sobre a forma como a Educação Ambiental é praticada pelos educadores ambientais e o perfil desses educadores, já que a área não pode ser vista somente como um campo dos profissionais da área de Ciências Naturais. Espera-se que este trabalho possa colaborar de alguma forma para a reflexão sobre a prática da Educação Ambiental e para a formação desses sujeitos, pois esse campo encontrase em constante transformação, no contexto político, econômico ou social.

Palavras-chave: Educação Ambiental. Educador Social. Desenvolvimento Local. Formação Profissional.

ABSTRACT: Given the complexity of the practice of environmental education and the diversity of subjects, of the most diverse areas of knowledge that work in this field, it is necessary to raise some questions about the role of these educators and what are the possibilities and collaborations that these can provide for development Of the territories where they are developed. Therefore, the objective of this work was to reflect on the actions of environmental education, in order to understand the meaning of this modality of education, since it is not only an activity of the formal educator. The article is based on a bibliographical review on the theme of environmental education and training of educators. Thus, this reflection starts from its historical process, going through the modalities of environmental education and finally arriving at the formation process of the same and in the way with the actions of environmental education are developed. Throughout the text it is sought to raise some considerations about the way environmental education is practiced by environmental educators and the profile of these educators, since the area can not be seen only as a field of professionals in the area of Natural Sciences. It is hoped that this work may contribute in some way to the reflection on the practice of environmental education and to the training of these subjects, once this field is in constant transformation, whether it be drawn by the political, economic or social context.

Keywords: Environmental Education. Social Educator. Local Development. Vocational Training.

RESUMEN: Dada la complejidad de la práctica de la educación y ladiversidad de los temas del medio ambiente, de diferentes áreas de conocimiento, en este esfuerzo, tenemos que plantear algunas preguntas sobre 


\begin{abstract}
* Biólogo, consultor ambiental, mestrando do Programa de Mestrado Profissional Gestão Social, Educação e Desenvolvimento Local. Centro Universitário UNA.

** Socióloga, mestre e doutora em Ciências da Educação e professora do Programa de Mestrado Profissional Gestão Social, Educação e Desenvolvimento Local. Centro Universitário UNA.
\end{abstract}

el papel de estos educadores y cuálessonlas posibilidades y colaboraciones que pueden ofrecer para el desarrolloubicación de los territoriosenlos que se desarrollan. Por lo tanto, el objetivo de este estudio fue reflexionar sobre las acciones de educación ambiental, de manera que hace que sea posible entender el significado de este tipo de educación, ya que no es sólo una actividad de educador formal. El artículo se basaen una revisión de la literatura sobre el tema y la formación de los educadores. Por lo tanto esta parte reflejo de su proceso histórico, a través de los métodos de la educación ambiental y, finalmente, llegar al proceso de formación de lamisma y enla forma se desarrollanlas acciones. A lo largo del texto, hemos tratado de plantear algunas consideraciones sobre cómo la educación ambiental es practicada por los educadores ambientales y el perfil de estos educadores, ya que la zona no puede ser visto sólo como un campo de los profesionales de las ciencias naturales. Se espera que este trabajo puede contribuir de alguna manera a reflexionar sobre la práctica de la educación y la formación de estos temas del medio ambiente, ya que este campo está en constante cambio, el contexto político, económico o social.

Palabras clave: Educación Ambiental. Educador Social. Desenvolvimento Local. Formación Profissional.

\section{INTRODUÇÃO}

A Educação Ambiental (EA) é uma prática bastante complexa, embora tenha sido instituída há vários anos. Essa institucionalização foi promovida principalmente a partir do campo ambiental, e não educacional, conforme afirmam Layrarguese Lima (2011). O movimento inicial começou em 1972, com a Conferência das Nações Unidas (ONU) sobre o Meio Ambiente e o marco inicial é considerado a Conferência de Tbilisi (1977), que deu novos rumos para norteamento prático dessa modalidade de educação. No Brasil, sua institucionalização se deu após vários movimentos ambientalistas, tendo início a partir da década de 1990, com o sancionamento da Política Nacional de Educação Ambiental (PNEA).

Entre suas complexidades, tem-se a forma com as ações são conduzidas pelos educadores ambientais, em virtude das diversas correntes ideológicas (SAUVÉ, 2005), que acabam influenciando na Educação Básica e nas demais ações não-formais de Educação Ambiental. De certa maneira, assim como a educação é um instrumento ideológico de reprodução social, também é a EA, por atravessar a disputa pela conservação ou transformação das condições sociais (LAYRARGUES, 2002).

Por se constituir em uma área passiva da colaboração de diversas áreas do conhecimento, torna possível a atuação de diversos profissionais no campo da EA e, consequentemente, na condução prática das atividades de sensibilização ambiental. No entanto, suas formações nem sempre acontecem no ensino superior, em virtude do não atendimento das recomendações da PNEA, que diz respeito à inserção temática nos currículos (PEQUENO; SILVA; COSTA, 2010). Assim, ocorre em alguns casos a prática de Educação Ambiental sem qualquer preparação teórica e prática.

O fato de ser um campo que não é ocupado somente pelo educador formal também interfere na prática dos educadores ambientais, levando, assim, à necessidade de buscar uma atuação mais ampla para esses sujeitos. 
1 Refere-se ao ensino formal da Educação Básica, que vai do Ensino Infantil, passando pelo Fundamental até o Ensino Médio.
E isso acaba por aproximá-los do papel do educador social, da ideia de um educador mais voltado para atuar em um contexto social mais geral, muitas vezes na informalidade (ARAÚJO; LUVIZOTTO, 2012; PINEL; COLODETE; PAIVA, 2012).

Em vista desse cenário e da complexidade do campo da Educação Ambiental, diversos autores, como Sato (2001), Jacobi (2003), Dias (2004) e Brügger (2004), levantam questionamentos sobre a forma como são conduzidas as ações e quais colaborações desse campo são possíveis para solucionar a complexa relação do homem com a natureza. Propõe-se, portanto, neste artigo, uma reflexão sobre esse campo que se encontra em constante questionamento e reformulação por parte de alguns estudiosos dessa área do conhecimento.

\section{EDUCAĈ̃̃ AMBIENTAL: UM POUCO DA SUA HISTŐRIA}

Para compreender a Educação Ambiental, é preciso conhecer o seu processo histórico, suas recomendações e considerações, para ser possível perceber que esse tipo de prática vai muito além da Educação Básica ${ }^{1}$, sendo estendida por toda a vida do cidadão. A prática da EA também deve ser analisada, pois sua construção é bastante complexa e, muitas vezes, a sua proposta é desconhecida pelos sujeitos, levando ao fracasso da sua execução e aplicação (DIAS, 2004; SATO, 2001). Exemplo disso é que a EA é frequentemente confundida com a simples prática de sensibilização, não sendo aplicada na sua transversalidade e totalidade, conforme as recomendações da PNEA (BRASIL, 2014).

Porém, para compreender um pouco da história da Educação Ambiental, é necessário recuar até a década de 1970, já que a discussão de uma educação para o meio ambiente iniciou-se em 1972, com a Conferência da ONU sobre o Meio Ambiente, realizada em Estocolmo (GUIMARÃES, 2013). Durante essa Conferência, deu-se início a um movimento que buscou discutir sobre essa área de conhecimento da educação, o qual deveria ser trabalhado em todos os níveis de ensino, com abordagem multidisciplinar (GUIMARÃES, 2013; LIMA, 1984).

No entanto, o fortalecimento do trabalho da Educação Ambiental aconteceu a partir da Conferência de Tbilisi (1977), contribuindo com diretrizes e sugestões para as práticas ambientais. No Brasil, o processo de institucionalização da EA manifestou-se a partir da década de 1990, com o sancionamento da Lei Federal $n^{0}$ 9.795/99 (BRASIL, 1999) e, posteriormente, com o Decreto $\mathrm{n}^{\circ}$ 4.281/2002 (BRASIL, 2002), que regulamentou essa mesma lei e incluiu o assunto em todos os níveis de ensino, nos órgãos e nas entidades integrantes do Sistema Nacional de Meio Ambiente (SISNAMA), nos órgãos públicos, nas entidades não governamentais, nos meios de comunicação e nos demais segmentos da sociedade (BRASIL, 2002). 
2 A sigla PRONEA é referente ao programa instituído em 1994, ao passo que a sigla ProNEA refere-se ao Programa instituído em 1999.
De 1990 a 2015, vários acontecimentos influenciaram a forma reflexiva do trabalho da Educação Ambiental na sociedade, começando pela Rio 92, que foi uma Conferência da ONU sobre Meio Ambiente e Desenvolvimento, com a presença de 170 países. Nesse evento, foi possível "reconhecer-se a insustentabilidade do modelo de desenvolvimento então vigente" (DIAS, 2004, p. 50). Esse evento colaborou para as premissas de Tbilisi, reorientando o trabalho da EA para o desenvolvimento sustentável.

Durante a Rio 92, com a participação do Ministério da Educação (MEC), foi redigida a Carta Brasileira para Educação Ambiental, na qual se reconheceu "[...] a Educação Ambiental como importante meio para viabilizar a sustentabilidade como estratégia de sobrevivência e melhoria da qualidade de vida humana no planeta" (BRASIL, 2014, p. 16).

Ainda em 1992, no "[...] contexto da institucionalização da Educação Ambiental no país, pode-se citar que houve estímulo à implantação de sistemas de gestão ambiental por setores empresariais, em consonância com leis e normas, como as da série ISO 14000" (BRASIL, 2014, p. 16).

Em desdobramento ao documento "Carta Brasileira para Educação Ambiental”, o MEC organizou, em Foz do Iguaçu, no mesmo ano de 1992, o $1^{\circ}$ Encontro Nacional de Centros de Educação Ambiental (CEAs) com a presença de coordenadores desses centros e técnicos das Secretarias de Educação, com a finalidade de traçar propostas e recursos institucionais para a temática (BRASIL, 2014).

Diante dos acontecimentos, é possível afirmar que o ano de 1992 foi marcante para a institucionalização da Educação Ambiental no Brasil. As ações não ficaram somente "com o intuito de criar instâncias de referência para a construção dos programas estaduais de Educação Ambiental", “[...] o [Instituto Brasileiro do Meio Ambiente e dos Recursos Naturais Renováveis] IBAMA e o [Ministério do Meio Ambiente] - MMA fomentaram a formação das Comissões Interinstitucionais de Educação Ambiental" (BRASIL, 2014, p. 17).

É importante destacar que a Constituição Federal de 1988 já fazia menção à Educação Ambiental, no inciso VI do art. 225, trazendo a necessidade de "[...] promover a Educação Ambiental em todos os níveis de ensino e a conscientização pública para a preservação do meio ambiente" (BRASIL, 1988).

Assim, devido à Constituição Federal de 1988 e aos acordos internacionais firmados na Rio 92, foi criado, em 1994, o Programa Nacional de Educação Ambiental (PRONEA) ${ }^{2}$, o qual foi executado pela Coordenação de Educação Ambiental do MEC e setores do MMA e do IBAMA, ligados à temática em questão (BRASIL, 2014). "O PRONEA previu três componentes: a) capacitação de gestores e educadores; b) desenvolvimento de ações educativas; c) desenvolvimento de instrumentos e metodologias" (BRASIL, 2014, p. 17). 
No ano seguinte, no Conselho Nacional de Meio Ambiente (CONAMA), foi criada a Câmara Técnica Temporária de Educação Ambiental. No entanto, somente em junho de 1996 é que aconteceu a primeira reunião, na qual "[...] foi discutido o documento intitulado 'Subsídios para a formulação de uma Política Nacional de Educação Ambiental', elaborado pelo MMA/IBAMA e pelo MEC" (BRASIL, 2014, p. 17).

Em 1999 foi criada a Diretoria do Programa Nacional de Educação Ambiental (ProNEA), vinculada à Secretaria Executiva do Ministério do Meio Ambiente, conquistando nesse mesmo ano a aprovação da demandada Política Nacional de Educação Ambiental, a Lei no 9.795, de 27 de abril de 1999. Com essa aprovação, a temática Educação Ambiental foi integrada ao Plano Plurianual (2000-2003), mas desta vez como um programa do governo federal, vinculado ao MMA (BRASIL, 2014).

As ações para fortalecimento da EA não pararam. No século XXI, os educadores ambientais resolveram reunir-se com o MMA para buscar apoio para as redes de EA, conseguindo que o Fundo Nacional do Meio Ambiente (FNMA) passasse a apoiar o fortalecimento e a estruturação de diversas redes de educação ambiental (BRASIL, 2014).

Finalmente, em junho de 2002, foi regulamentada a Lei $n^{\circ} 9.795 / 99$, por meio do Decreto ${ }^{\circ} 4.281 / 2002$, definindo a sua composição e as competências do Órgão Gestor da PNEA (BRASIL, 2014).

Percebe-se, na cronologia apresentada sobre a institucionalização da Política Nacional de Educação Ambiental, que os esforços foram intensos por todos os interessados na criação de uma política e de novos instrumentos regulatórios para a Educação Ambiental. E os esforços ainda são constantes para solucionar os diversos problemas e ajustes que existem no campo da Educação Ambiental. Como exemplo, podem-se citar as tendências da EA, a forma como as ações são executadas pelos educadores, os processos de formação, entre outros assuntos que perpassam pelo campo da Educação Ambiental.

\subsection{As modalidades de Educação Ambiental}

A necessidade de promover a Educação Ambiental em todos os níveis de ensino é algo que está previsto na Política Nacional de Educação Ambiental, em seu art. $2^{\circ}$, o qual assevera que: "a Educação Ambiental é um componente essencial e permanente da educação nacional, devendo estar presente, de forma articulada, em todos os níveis e em todas as modalidades do processo educativo, em caráter formal e não formal" (BRASIL, 1999). Mas constata-se que, antes da PNEA e até mesmo da Constituição Federal de 1988, a recomendação já estava posta pela Política Nacional de Meio Ambiente (PNMA), Lei $\mathrm{n}^{\circ}$ 6.938, de 31 de agosto de 1981 , no art. $2^{\circ}$, que inclui, entre os seus princípios, "[...] a Educação Ambiental em todos os níveis de 
ensino, inclusive a educação da comunidade, objetivando capacitá-la para participação ativa na defesa do meio ambiente" (BRASIL, 1981).

Diante dessas recomendações postas pelas leis brasileiras, faz-se necessária a promoção da Educação Ambiental; mas, percebe-se que o artigo $2^{0}$ da Lei 9.795/99 não faz referência à educação informal, deixando de fora as ações educacionais que são realizadas fora dos espaços institucionais (BRASIL, 1999). No entanto, o Tratado de Educação Ambiental para Sociedades Sustentáveis e Responsabilidade, estabelecido em 1992 no Fórum Global, e a recomendação CONAMA $\mathrm{n}^{0}$ 11, de 04 de maio de 2011, fazem menção às três modalidades de educação - formal, não formal e informal, quando se refere à implantação do CEA (BRASIL, 2014; CONAMA, 2011).

Assim, é importante distinguir a diferença dessas três modalidades de educação, pois cada uma apresenta suas particularidades e colaborações, as quais acabam interferindo na forma como é produzido e reproduzido o conhecimento.

Segundo Libâneo (1998, p.88) a educação "[...] formal refere-se a tudo o que implica uma forma, isto é, algo inteligível, estruturado, o modo como algo se configura. Educação formal seria, pois, aquela estrutura organizada, planejada intencionalmente, sistemática”. Esta modalidade é representada pelas escolas e faculdades, por possuírem todos os pré-requisitos descritos pelo autor.

$\mathrm{Na}$ educação formal a figura do educador é o professor, o qual é responsável pelo ensino e pela aprendizagem de conteúdos que se encontram sistematizados e organizados conforme as diretrizes educacionais, requerendo tempo e local específico para que aconteça todo o processo educacional (GOHN, 2006).

Conforme o artigo $9^{\circ}$ da Política Nacional de Educação Ambiental, a Educação Ambiental formal é representada pela Educação Básica (Educação Infantil; Ensino Fundamental e Ensino Médio), Educação Superior, Educação Especial, Educação Profissional e Educação de Jovens e Adultos (BRASIL, 1999).

Nesses espaços de educação formal, a Educação Ambiental encontra-se garantida por meio dos PCNs, a partir do tema transversal meio ambiente. Além dos PCNs, têm-se ainda as "Diretrizes Curriculares Nacionais para a Educação Ambiental”, aprovadas pelo Conselho Nacional de Educação (BRASIL, 2014).

A segunda modalidade é a educação não formal, definida como "[...] aquelas atividades com caráter de intencionalidade, porém com baixo grau de estruturação e sistematização, implicando certamente relações pedagógicas, mas não formalizadas" (LIBÂNEO, 1998, p. 89). Libâneo (1998) destaca que as ações extraescolares, que são promovidas pelas escolas, são um tipo de educação não formal, por apresentarem conhecimentos complementares em conexão com a educação formal. 
Para Gohn (2006, p.28), a educação não formal é vista como aquele processo que se aprende "[...] 'no mundo da vida', via os processos de compartilhamento de experiências, principalmente em espaços e ações coletivos cotidianos". Gohn (2006, p. 29) traz o educador, nessa modalidade de ensino, como o sujeito com o qual se interage ou se integra.

Na educação não-formal [sic], os espaços educativos localizam-se em territórios que acompanham as trajetórias de vida dos grupos e indivíduos, fora das escolas, em locais informais, locais onde há processos interativos intencionais (a questão da intencionalidade é um elemento importante de diferenciação).

Assim, diante da opinião desses autores, pode-se afirmar que o trabalho de Educação Ambiental não formal pode ser representado pelas ONGs, associações de bairros, museus, entre outros, que desenvolvem trabalhos de preservação e sensibilização ambiental, já que nesses locais existe certa intencionalidade nas ações desenvolvidas.

Já a educação informal é definida por Nassif (1980 apud LIBÂNEO, 1998) como o processo contínuo de aquisição de conhecimentos e competências que não se localizam em algum quadro institucional. Libâneo (1998) acrescenta que a educação informal contribui para compreender a totalidade dos processos educacionais, pois perpassa as modalidades de educação que apresentam todo um processo de institucionalização.

Na educação informal, o papel do educador está na figura de pais, familiares, todos aqueles que estão no seu ciclo de amizade, inclusive os meios de comunicação, que de alguma forma colaboram com o processo de socialização dos indivíduos (GOHN, 2006). "A educação informal socializa os indivíduos, desenvolve hábitos, atitudes, comportamentos, modos de pensar e de se expressar no uso da linguagem, segundo valores e crenças de grupos que se frequenta ou que pertence por herança, desde o nascimento" (GOHN, 2006, p. 29).

Como exemplo de EA informal, podem-se descrever as ações isoladas desenvolvidas por cidadãos para sensibilizar outras pessoas sobre a importância da preservação e/ou recuperação de nascentes. Trata-se de uma educação produzida pelas experiências da vida, fora dos espaços institucionais e repassadas para as gerações mais novas, conforme descreve Libâneo (1998, p. 73):

A educação é, também, uma prática ligada à produção e reprodução da vida social, condição para que os indivíduos se formem para a continuidade da vida social. Neste sentido, é inevitável que as gerações adultas cuidem de transmitir às gerações mais novas os conhecimentos, experiências, modos de ação que a 
3 Não é objeto deste estudo abordar as correntes em Educação Ambiental existentes nesse campo. humanidade foi acumulando em decorrência das relações incessantes entre o homem e o meio natural e social.

Segundo a "Carta aberta de educadoras e educadores por um mundo justo e feliz!", elaborada na $2^{\text {a }}$ Jornada Internacional de Educação Ambiental, durante a Rio+20, "[...] a educação é sempre baseada em valores: nunca houve, não existe, nunca haverá neutralidade na educação, seja ela formal, não formal, informal, presencial ou a distância" (BRASIL, 2014, p.92). Logo, pode-se dizer que não importa a modalidade de Educação Ambiental - formal, não formal ou informal -, o importante é que haja educação para preservação ambiental e que esta promova a consciência crítica dos cidadãos para analisar os entraves da relação homem-natureza.

Cabe ressaltar que essas modalidades de educação ainda estão sujeitas às macrotendências ou correntes ${ }^{3}$ em Educação Ambiental que acabam influenciando no modo com o meio ambiente é trabalhado e no enfoque do trabalho do educador ambiental (ALBANUS; ZOUVI, 2013; LAYRARGUES; LIMA, 2011; SAUVÉ, 2005). Segundo Sauvé (2005), o trabalho da EA está sujeito a 15 correntes, variando da mais tradicional, originada nas décadas de 1970 e 1980, a outras mais modernas que surgiram recentemente com um novo olhar sobre a relação do ser humano com o meio ambiente.

\subsection{A Educação Ambiental na prática}

No cenário brasileiro do século XXI, mesmo após várias conferências mundiais e ações para criação de uma política exclusiva para a Educação Ambiental, sua prática é, entretanto, bastante questionada e de pouca aplicação por parte de alguns setores da sociedade. Um exemplo é a Política Nacional de Resíduos Sólidos, Lei $\mathrm{n}^{0}$ 12.305, a qual, mesmo tendo a Educação Ambiental como instrumento, não garante a aplicação de forma eficaz de suas ações (BRASIL, 2010). Ainda nesse caminho, ocorrem situações como as campanhas contra a dengue, que acontecem principalmente nos períodos chuvosos, quando são desenvolvidas ações de técnicos municipais e até mesmo envolvendo o Exército Brasileiro, anúncios em rede nacional e local etc. Mas, apesar de toda a mobilização, o problema continua persistindo todos os anos.

A sociedade ainda não está suficientemente engajada para uma Educação Ambiental em que haja preservação e preocupação com os recursos naturais. Executam-se ações que acontecem esporadicamente, principalmente quando existe necessidade de solucionar um problema momentâneo ou para trabalhar algum tema alusivo à temática ambiental. Segundo Layrargues (2002, p.12): 
ambiental. Forma-se uma conjuntura onde a humanidade como um todo aparece tanto como responsável pela atual crise ambiental como vítima de seus efeitos. Dessa forma, consolida-se um consenso universal apaziguador, pois assim as vítimas não mais podem responsabilizar os culpados, já que todos são iguais perante a "catástrofe ecológica".

Ao mesmo tempo, Layrargues (2002) afirma que é preciso rever o sentido ideológico da Educação Ambiental, já que existem outras macrotendências, em virtude da necessidade de alguns educadores em nomear e distinguir novos perfis ideológicos de Educação Ambiental. Entre essas macrotendências, tem-se a visão crítica, bem diferente da visão convencional, já que ela busca ampliar as análises e reflexões sobre a relação do ser humano com os recursos naturais.

Essa reflexão sobre o trabalho da EA também é levantada por Brügger (2004), quando questiona se realmente temos uma Educação Ambiental ou um adestramento ambiental. Para essa autora, as pessoas são levadas a executar determinadas funções e tarefas sem se sentirem vítimas das suas próprias ações, pois a sociedade é bombardeada de informações que vinculam valores profundamente consumistas. Tais mensagens reproduzem a ideologia da sociedade industrial, acelerando o ritmo de produção e consumo (BRÜGGER, 2004).

Uma prova dessa falta de envolvimento é a situação atual dos reservatórios de água no Brasil: a população, mesmo acompanhando os noticiários sobre o assunto, não parece estar convencida de que é necessário questionar a relação dos seres humanos e dos grandes setores produtivos com o meio ambiente. Surge daí o questionamento sobre o que tem sido feito e como está sendo trabalhado o meio ambiente com base nos Programas de Educação Ambiental reconhecidos pelo Ministério do Meio Ambiente (BRASIL, 2015b).

Para Reigota (1998, p.48), a proposta da Educação Ambiental é construída na transmissão e construção de conhecimento, pois "permite que o processo pedagógico aconteça sob diferentes aspectos, que se complementam uns aos outros". Sem dúvida, é preciso repassar conhecimento. Mas é necessário, principalmente, que os trabalhos de Educação Ambiental incorporem ambas, a visão convencional e a visão crítica, para que seja possível refletir as complexas relações dos sistemas ecológicos e dos sistemas empresarias (indústria do papel, vidro, plástico, tecnológica, entre outras). Também é fundamental que se possa, ao mesmo tempo, questionar o que se encontra envolvido nessa complexa relação desses sistemas.

Essa ideia definida por Reigota (1998), Layrargues (2002) e Brügger (2004), de uma proposta pedagógica baseada nesses princípios, acaba não ocorrendo, por falta de capacitação dos educadores ou, ainda, pela ausência da 
introdução da Educação Ambiental nos processos de formação ou então pela dificuldade em lidar com práticas interdisciplinares (AZEVEDO; ANDRADE, 2007; SATO, 2001).

Uma vez que a prática da EA envolve diferentes áreas de conhecimento para que se possa reelaborar a produção de novos conhecimentos e que o resultado desse processo é aplicado na transformação da sociedade (GUIMARÃES, 2013), é preciso que o sujeito esteja apto a praticar a interdisciplinaridade no seu processo de trabalho ambiental. Assim, percebe-se que a prática da EA implica o enfrentamento de obstáculos como a falta de experiência em lidar com ações interdisciplinares e o desconhecimento do que é um trabalho de EA. Nesse caso, ambos os obstáculos envolvem o processo de capacitação ou formação dos educadores.

Pombo (2006, p.210) defende que "[...] a interdisciplinaridade traduz-se na constante emergência de novas disciplinas que não são mais do que a estabilização institucional e epistemológica de rotinas de cruzamento de disciplinas”. Ela ainda completa que o fenômeno interdisciplinar torna mais articulado o conjunto dos diversos saberes.

Outra dimensão da interdisciplinaridade que não se pode deixar de destacar é a de que a "[...] interdisciplinaridade se caracteriza pela intensidade das trocas entre os especialistas e pelo grau de integração real das disciplinas no interior de um mesmo projeto" (JAPIASSU, 1976 apud THIESEN, 2008, p. 548).

Pode-se, então, considerar que a prática da interdisciplinaridade possibilita a troca e a integração dos diversos conhecimentos, o que, segundo Freire (1996), deve proporcionar ao educador habilidades como saber ouvir e dialogar, de forma que permita a troca mútua do conhecimento entre os envolvidos no processo educacional. "A formação do educador ambiental pressupõe um ambiente em que todos tenham voz e possam trocar experiências, rever seus conhecimentos e produzir novos sentidos a partir de uma perspectiva crítica" (ABREU; MOURA, 2013, p.401).

Percebe-se que existe uma dificuldade, por parte dos educadores, em aplicar o princípio interdisciplinar, apesar de ele ser bastante antigo nas práticas de Educação Ambiental. Para Sato (2001, p. 24):

Embora haja reconhecimento de que, atualmente, as ciências buscam um diálogo entre suas fronteiras do conhecimento, há certa resistência fetichista contra a contaminação de uma área a outra e os limites das fronteiras do conhecimento ainda permanecem fortes, prejudicando o diálogo necessário para os estudos ambientais. $\mathrm{E}$ as experiências de cada uma das partes perdem em significação quando não existe o livre entrelaçamento das várias manifestações da vida.

É preciso entender, de acordo com Sato (2001), a complexidade ambiental, já que a dimensão ambiental 
4 A legislação referida por Gerra e Orsi (2013) diz respeito à Lei $\mathrm{n}^{\circ}$ 9.795/99, especificamente ao artigo 10 desta lei (BRASIL, 1999). está presente nas diversas áreas do conhecimento. Para apreender a complexidade ambiental, é preciso compreender a Teoria da Complexidade defendida por Morin (2005, p. 192), o qual afirma que "a complexidade não tem metodologia, mas pode ter seu método". E, na busca de um conceito para o método, conclui-se que não é possível definir um conceito, pois é preciso continuar restabelecendo as articulações, "para nunca esquecermos as totalidades integradoras".

O segundo obstáculo seria lidar com a carência na introdução da Educação Ambiental nos diversos currículos. De acordo com Sato (2001, p. 29), "[...] a carência da introdução da EA nos currículos de graduação, pós-graduação e cursos de formação continuada é fortemente presente no cenário nacional e em muitos outros países latino-americanos". Essa carência reflete-se na forma como são trabalhados e executados os Programas de Educação Ambiental, abordados somente em ocasiões comemorativas, como dia da árvore ou meio ambiente, e não configurado como um projeto para construção dos valores sociais (SATO, 2001).

A esse respeito, Pequeno, Silva e Costa (2010), Gerra e Orsi (2013) e Pequeno (2016) salientam que a falta de formação dos educadores de fato é um dos problemas, já que a Educação Ambiental "[...] é um tema relativamente recente ou ausente nos cursos de formação docente [...]" (PEQUENO, 2016, p. 216).

No entanto, não deveria ser considerado ausente, uma vez que a PNEA traz "[...] a incorporação da dimensão ambiental na formação, especialização e atualização dos educadores de todos os níveis e modalidades de ensino" (BRASIL, 2014, p. 40). Percebe-se que essa recomendação não é algo recente, já estava imposta quando a lei foi sancionada e reafirmada perante as ações do ProNea, faltando, assim, ações efetivas por parte do MEC. Ao mesmo tempo, a inserção da temática EA nos cursos de formação pode ser prejudicada mediante as lacunas existentes na própria Lei $\mathrm{n}^{0}$ 9.394/96 - Lei de Diretrizes e Bases da Educação Nacional (LDBN). Para Gerra e Orsi (2013, p. 33-34), a legislação educacional:

[...] não estabelece claramente em seu texto disposições para a mesma. Assim, em muitos casos, a EA continua sendo tratada de forma tradicional e conservadora nas universidades brasileiras com a criação de disciplinas isoladas no currículo de cursos de graduação, contrárias à própria legislação ${ }^{4}$. Ignorando a história, os princípios e a revelia da Lei da EA [...].

Diante desses desencontros e dessa falta de capacitação dos educadores, ocorre que muitas vezes as ações são realizadas de forma pontual, conforme apontado por Sato (2001) e reafirmado por Pequeno, Silva e Costa (2010, p.35), quando diz que as ações de EA “[...] ocorrem, em sua 
maioria, numa perspectiva pontual como datas comemorativas, palestras, oficinas, coleta seletiva e monografias, de forma ampla e sem especificação: 'ações práticas', 'projetos', extensão, 'pesquisa', 'atividades práticas e de investigação”. Pequeno, Silva e Costa (2010) ainda enfatizam que as ações podem ocorrer de "forma muito vaga", o que é reafirmado por Gerra e Orsi (2013, p. 31), quando analisam as práticas pedagógicas dos educadores:

Sua formação na EA supervaloriza as práticas sobre temas ambientais na forma de vivências de sensibilização, as "datas ecológicas”, a reciclagem de resíduos - sem necessariamente discutir o modelo neoliberal e os padrões de extração de bens, produção, distribuição, consumo e descarte de resíduos - dentre outras ações individuais e pontuais, sem reflexão crítica, em detrimento do desenvolvimento de valores ambientais, princípios éticos, a ação coletiva e o engajamento político no enfrentamento das questões e dos conflitos ambientais.

Nesse sentido, é preciso buscar um elo entre esses projetos que trazem as ocasiões comemorativas e a construção dos valores sociais. Mas, para isso acontecer, seria preciso convidar os sujeitos envolvidos a participarem de forma construtiva e permanente do processo de formação crítica do cidadão, para possível avaliação da complexa relação do homem como o meio no qual se encontra inserido.

No trabalho de Educação Ambiental, "[...] é preciso que o educador trabalhe intensamente a integração entre o ser humano e ambiente e se conscientize de que o ser humano é natureza e não apenas parte dela" (GUIMARÃES, 2013, p. 30).Esse autor entende que, quando esse ideal é assimilado pelo homem, acontece uma mudança no comportamento deste com o meio ambiente. Assim, o indivíduo passa asentir-se integrado em uma unidade "ser humano/natureza", que não favorece a dominação de um sobre o outro.

\section{OS PROGRAMAS DE EDUCAÇÃO AMBIENTAL E PARTICIPAÇÃO SOCIAL}

Nessas condições, os programas de Educação Ambiental podem sofrer impactos em virtude das "falhas" da formação. Se, de um lado, os professores encontram-se sem formação, do outro estão os técnicos e os demais profissionais das diversas áreas, e estes também estão sujeitos à mesma carência na formação. Para Gerrae Orsi (2013), diante da falta de espaço da EA nas escolas, os trabalhos geralmente são desenvolvidos por meio de ações educativas não formais de educação; todavia, essas ações, muitas vezes, não consideram a contextualização do local ou desconsideram a dimensão social dos sujeitos envolvidos.

É importante destacar que um programa de Educação Ambiental deve ser elaborado com a ajuda de todo o 
5 Não é o objetivo deste estudo abordar os diferentes conceitos existentes no universo educacional. Portanto, refere-se à educação/ formação de maneira geral sem distinções. público envolvido, sejam os agentes comunitários, as igrejas, as associações, os setores privados, as escolas, ONGs etc., para que estes se sintam parte integrante do projeto. Na visão de Jacobi (2003), deve-se envolver um conjunto de diversos atores, no sentido de que seja algo interdisciplinar, que envolva os vários conhecimentos do universo educacional. A falta da interdisciplinaridade na comunidade, no sentido de envolver vários especialistas/profissionais, pode ser compensada pela experiência pessoal de cada cidadão envolvido. $\mathrm{O}$ conhecimento adquirido pela vida também é válido para a construção de qualquer projeto que venha a colaborar com os interesses sociais, pois se trata de um aprendizado social com base“[...] no diálogo e na interação em constante processo de recriação e reinterpretação de informações, conceitos e significados, que podem se originar do aprendizado em sala de aula ou da experiência pessoal do aluno", conforme afirma Jacobi (2003, p. 198).

É preciso entender que "[...] há ideias universalmente difundidas, entre elas a de que não há idade para se educar, de que a educação se estende pela vida e que ela não é neutra" (GADOTTI, 2000, p. 4). A humanidade precisaria compreender que os valores ambientais também são construídos da mesma forma que os outros valores sociais devem ser seguidos pela vida toda em prol da conservação do Planeta. Ainda para Gadotti (1991, p. 4):

Todo ser humano é capaz de aprender e de ensinar e, no processo de construção do conhecimento, todos os envolvidos aprendem e ensinam. O processo de ensino-aprendizagem é mais eficaz quando o educando participa, ele mesmo, da construção do seu conhecimento, fazendo "seu" o conhecimento e não apenas "aprendendo" o conhecimento.

Entretanto, para que haja a participação em torno de um projeto dessa natureza, deve-se considerar o que Dias (2004) alerta: para que os objetivos da EA não sejam definidos sem se levar em conta as realidades econômicas, sociais e ecológicas da sociedade, o educador deve convidar o educando a se sentir parte presente dos projetos pedagógicos: "Pelos seus objetivos e funções, a EA é necessariamente uma forma de prática educacional sintonizada com a vida da sociedade" (DIAS, 2004, p. 148).

Conforme salientam Giaretta, Fernandes e Philippi Jr. (2012, p. 532), a própria Constituição de 1988 regulamenta o direito à participação popular no seu artigo $1^{\mathrm{o}}$ : “[...] não só dando sinais quanto ao direito à participação como promovendo um avanço significativo com a participação direta do povo".

Observa-se, assim, que é preciso fomentar a preparação não só dos educadores, mas de todos cidadãos para que participem a partir da formação, seja ela por meio de capacitações, treinamentos ou reciclagem ${ }^{5}$. O intuito é que os cidadãos sejam sensibilizados ou mesmo informados 
sobre as complexas relações ambientais, lembrando que a informação é necessária em alguns casos, quando ainda existe falta de conhecimento por parte do cidadão. A esse respeito, Sgarbi et al. (2016) aduzem que o maior desafio da educação contemporânea é o acesso democrático dos saberes, de modo que possibilite o diálogo entre eles e a criação de valores ético-culturais e socioambientais. Ressaltam, também, que o desafio maior está na formação de cidadãos participativos e capazes de relacionarem em um ambiente cada vez mais completo mediante a globalização e demandante da produção de bens materiais e simbólicos (SGARBI et al., 2016).

De acordo com pesquisa realizada por Nunes, Philippi Jr. e Fernandes (2012) sobre a atuação de conselheiros do meio ambiente na gestão ambiental de determinado município, percebeu-se que "[...] os representantes devem estar qualificados para representar, discutir e opinar sobre assuntos relacionados ao Conselho e aos problemas ambientais enfrentados pelo município" (p. 59).

Partindo desse princípio, o Programa Nacional de Educação Ambiental (ProNEA), propõe uma mudança cultural na sociedade, sobre a qual se entende que são necessárias "[...] mudanças nos desejos e formas de olhar a realidade, nas utopias e nas necessidades materiais e simbólicas, nos padrões de produção e consumo, lazer e religiosidade" (BRASIL, 2005, p. 18). Assim, o ProNEA busca contribuir para a valorização da diversidade e da identidade local, de forma que se tenha a construção de uma sociedade atuante e sustentável e, consequentemente, melhoria da qualidade (BRASIL, 2014).

A Agenda 21 relata que o ensino é fundamental, seja ele formal ou informal, para promover o desenvolvimento sustentável e aumentar a capacidade de o cidadão conseguir abordar as questões ambientais e do desenvolvimento, aindaque o "ensino básico sirva de fundamento para o ensino em matéria de ambiente e desenvolvimento", mas tendo o desenvolvimento como parte essencial do aprendizado. O capítulo 36 da Agenda 21 assevera que:"Tanto o ensino formal como o informal são indispensáveis para modificar a atitude das pessoas, para que estas tenham capacidade de avaliar os problemas do desenvolvimento sustentável e abordá-los" (BRASIL, 2015a).

De certa forma, muitas dessas ações previstas nos objetivos do ProNEA e recomendadas pela Agenda 21 são aplicadas por meio dos Programas de Educação Ambiental que são desempenhados por empresas privadas no estado de Minas Gerais (GERRA; ORSI, 2013). Cabe ressaltar que, quando aplicada por esse setor, sua aplicação muito provavelmente não é uma execução de livre e espontânea vontade. O Programa de Educação Ambiental é exigido devido ao processo de licenciamento do empreendimento, conforme recomendações do processo de regularização ambiental do estado de Minas Gerais. Assim, as empresas responsáveis pelos estudos ambientais devem adotar o Termo de 
6 Conforme a Deliberação Normativa $\mathrm{n}^{0}$ 74/04 do Conselho de Política Ambiental (COPAM)/MG.
Referência para Educação Ambiental não formal, elaborado pela Secretaria de Estado de Meio Ambiente e Desenvolvimento Sustentável de Minas Gerais (SEMAD). Esse documento fornece subsídios para a elaboração e a implantação de programas de Educação Ambiental durante as fases de implantação e operação do empreendimento ${ }^{6}$ (MINAS GERAIS, 2015).

Como exemplo dos programas de Educação Ambientais desenvolvidos pela iniciativa privada em cumprimento às exigências legais, podem ser citados os trabalhos da Companhia Vale do Rio Doce (Vale) e pela Arcelor Mittal Brasil, ambas do setor minerário. Outras ações educacionais também são realizadas no estado de Minas Gerais por meio de ONGs como o Instituto Terra Brasilis de Desenvolvimento Socioambiental e Fundação Biodiversitas ou por intermédio da iniciativa pública com o Projeto Sala Verde, desenvolvido pela Secretaria Municipal de Meio Ambiente de Belo Horizonte e Programa "AmbientAÇÃO", que é coordenado pela Fundação Estadual de Meio Ambiente, órgão vinculado à SEMAD (MINAS GERAIS, 2015). É importante ressaltar que cada uma dessas instituições desenvolve trabalhos de EA focados em algum aspecto ambiental, seja ele voltado para a preservação da fauna ou para a relação socioambiental.

De qualquer maneira, pode-se afirmar que a educação é considerada a base para a mudança da atitude das pessoas. Essa afirmação pode ser confirmada pelo item 36.3 da Agenda 21, a qual esclarece que o ensino "[...] é também fundamental para conferir consciência ambiental e ética, valores e atitudes, técnicas e comportamentos em consonância com o desenvolvimento sustentável e que favoreçam a participação pública efetiva nas tomadas de decisão" (BRASIL, 2015a, [s. p.]).

Quando a Agenda 21 trata sobre o aumento da consciência pública, alerta que é preciso sensibilizar o público para os problemas do meio ambiente e do desenvolvimento, fazendo perceber que a participação da população é fundamental, além de "[...] fomentar o senso de responsabilidade pessoal em relação ao meio ambiente e uma maior motivação e dedicação em relação ao desenvolvimento sustentável” (BRASIL, 2015a, [s. p.]).

\section{O EDUCADOR SOCIAL E O DESENVOLVIMENTO LOCAL}

Para Layrarguese Lima (2011), a partir do momento em que os educadores ambientais percebem que a natureza, o meio ambiente, a sociedade e a educação podem apresentar diferentes concepções, essas diferenças acabam interferindo nas diferentes concepções de Educação Ambiental. A partir daí, essa prática passa a sofrer interferência de outras áreas do conhecimento e possibilita novos olhares para a relação complexa do meio ambiente. Layrarguese Lima (2011, p.6) consideram que: 
Nesse processo, o desenvolvimento dessa prática educativa [Educação Ambiental] e sua respectiva área de conhecimento se ramificaram em várias e distintas possibilidades de acordo com as percepções e formações profissionais de seus protagonistas, com os contextos sociais nos quais se inseriam e com as mudanças experimentadas ao longo do tempo pelo próprio ambientalismo.

Assim, deve-se notar que a EA não pode ser vista somente como um campo dos profissionais da área das Ciências Naturais, mas que vem tendo participação de outras áreas como "[...] Ciências Exatas e da Terra, Ciências Sociais Aplicadas, Engenharias, Ciências da Saúde, Linguística, Letras e Artes, configurando-se uma composição multidisciplinar" (KAWASAKI; MATOS; MOTOKANE, 2006, p. 119).

Conforme já mencionado anteriormente, a Educação Ambiental não se constitui como um campo exclusivo de educadores formais, e estes nem sempre desenvolvem ações sozinhos, pois muitas vezes recebem colaboração dos educadores não formais, por meio de atuação de terceiros nesse processo de sensibilização ambiental (GERRA; ORSI, 2013).

Sem dúvida, diante da diversidade de sujeitos que podem atuar como educadores ambientais (KAWASAKI; MATOS; MOTOKANE, 2006), além da diversidade de macrotendências nesse campo, a qual, de certa forma, apresenta influência de outras áreas do conhecimento (LAYRARGUES; LIMA, 2011), seria pertinente encontrar uma nomenclatura mais ampla para nomear esses educadores.

Pode-se, entretanto, aproximar a atuação dos profissionais da Educação Ambiental do campo do educador social. O educador social tem seu fundamento nos princípios da Pedagogia Social, que é definida por Pinel, Colodete e Paiva (2012, p. 5-6) como:

[...] uma ciência que se produz pela prática (e práxis) educacional/pedagógica (bem como social e psicossocial) não formal (e formal), que dentre outras tarefas-saberes, propõe ser uma forma pedagógica e educacional de trabalho social de ajuda (de acordo com as necessidades) e de revitalização crítica da solidariedade e cidadania, havendo mais perspectivas que podem ganhar sentido, dependendo do contexto sócio-histórico e da realidade vivida, como o esforço de inserir o educando em movimentos políticos [...], luta por uma ecologia social (e qualidade de vida), socialização em geral nas escolas, por exemplo, Educação Moral e Cívica, Educação para a Justiça - dentre outros.

Caliman (2011 apud PINEL; COLODETE; PAIVA, 2012) define a Pedagogia Social como uma ciência prática, 
social e educativa, não formal, que justifica e compreende, em termos mais amplos, a tarefa da socialização e, em modo particular, a prevenção e a recuperação no âmbito das deficiências da socialização e da falta de satisfação das necessidades fundamentais.

É possível perceber que a Pedagogia Social “[...] é uma disciplina científica; uma teoria que fornecerá as ferramentas para a Educação Social, que é uma práxis" (PINEL; COLODETE; PAIVA, 2012, p. 2). Assim, é possível compreender que a Pedagogia Social fornece embasamento para as práticas dos educadores ambientais e que, conforme Pinel, Colodete e Paiva (2012), um agente multiplicador colabora com o processo de formação dos demais sujeitos na sua prática social.

Machado (2009) preleciona que, na Pedagogia Social, Paulo Freire pode ser visto como uma das mais significativas referências nessa área, apesar de não utilizar essa nomenclatura na sua obra. Uma evidência da importância de Paulo Freire para a Pedagogia Social está nesta passagem extraída da sua obra "Pedagogia da Autonomia: saberes necessários à prática educativa”, na qual menciona que se deve: "[...] saber que ensinar não é transferir conhecimento, é fundamentalmente pensar certo - é uma postura exigente, difícil, às vezes penosa, que temos de assumir diante dos outros e com os outros, em face do mundo e dos fatos, ante nós mesmos" (FREIRE, 1996, p.21). Essa fala de Freire (1996) elucida muito o papel do educador social, o qual deve estar sempre disposto a ensinar, ainda mais quando estão envolvidos hábitos sociais e culturais difíceis de serem modificados.

Cada tipo de educação exige um tipo de educador, para que "o processo de ensino-aprendizagem se efetive". No caso da Educação Ambiental não formal e informal, o educador social pode ser este profissional (ARAÚJO; LUVIZOTTO, 2012, p. 75).

Portanto, o papel do educador social, no que se refere ao contexto ambiental, é a de um sujeito responsável em promover a educação não formal, colaborando com a sensibilização dos sujeitos envolvidos no processo de entendimento dos problemas ambientais, seus impactos e, principalmente, da importância da participação dos cidadãos no processo de preservação ambiental.

Segundo Gohn (2009), o papel do educador social é algo que acontece em uma perspectiva comunitária, a partir de uma aprendizagem em uma via de mão dupla. Ele aprende e ensina ao mesmo tempo, tendo o diálogo como meio de comunicação, o que aproxima do papel do educador ambiental.

Observa-se, assim, que a atuação desses educadores sociais assemelha-se muito à do educador ambiental, o qual, de certa forma, tem muito a colaborar para o trabalho da Educação Ambiental e promover o desenvolvimento local. Isso se aproxima da visão de Montenegro-Gómez (2002), segundo o qual o desenvolvimento local somente 
é possível com a participação das comunidades para a escolha de quais ações devem ser implementadas, para que haja garantia de desenvolvimento.

O desenvolvimento local, segundo Martins, Vaz e Caldas (2010, p. 564), “[...] apresenta vários significados, comportando as diferentes dimensões em que se exerce a cidadania, e tem condições de criar um espaço de interação entre cidadãos, recuperando a iniciativa e a autonomia na gestão do que é público".

Para Tenório, Dutra e Magalhães (2004, p. 1), o desenvolvimento local é visto como uma ação coordenada entre a sociedade civil e o poder público, com base na participação e democratização, em "[...] prol do bem-estar social, econômico, político e cultural de um dado território". Partindo da definição apresentada pelos autores, percebe-se uma complementação no sentido atribuído ao desenvolvimento local, com ação participativa e democrática, cuja sociedade civil e a pública interagem para resolver os problemas do território.

No que se refere à prática de Educação Ambiental, o educador social pode ser o responsável por articular os saberes e fazeres dos sujeitos locais para atuar sobre complexas questões socioambientais, buscando a reflexão e o engajamento para uma proposta pedagógica centrada na criatividade e na emancipação desses sujeitos. Deve ter em vista a mudança de comportamento e atitudes, com foco no desenvolvimento da organização social e na participação coletiva (JACOBI; TRISTÃO; FRANCO, 2009).

Conforme Montenegro-Gómez (2002), o enfoque do local no desenvolvimento surgiu nos anos 1980, após os questionamentos, tanto em nível nacional como regional, sobre a implementação de políticas e programas de desenvolvimento, incorporando a questão social e política às propostas de desenvolvimento. O local passa a ser compreendido como o lugar que: "[...] não deve ser compreendido apenas como o espaço onde se realizam as práticas diárias; mas também como aquele no qual se situam as transformações e a reprodução das relações sociais de longo prazo, bem como a construção física e material da vida em sociedade" (ALBAGLI, 1998, p. 183).

Fragoso (2005) completa afirmando que o local é uma espécie de duplo caráter, em que, por um lado, representa o locus da vida social, com os acontecimentos, os fenômenos e as práticas sociais, mas que, por outro lado, está propício a interferências externas. Logo, pode-se considerar que o local se refere ao espaço onde acontecem as representações sociais, seja o bairro, a residência, a escola ou os próprios programas de Educação Ambiental, desenvolvidos pelas ONGs, mas sempre pensando nesses espaços como o locus da transformação e do desenvolvimento dos sujeitos e para os sujeitos.

Percebe-se que essa visão do desenvolvimento local está de, certa forma, relacionada à participação e à transformação social, colaborando com o ProNEA e aproximando 
do sentido da participação proposta por Dias (2004), Giaretta, Fernandes e Philippi Jr. (2012) e Toro e Werneck (1995). Assim, as práticas de Educação Ambiental têm muito a colaborar para a promoção do desenvolvimento local, seja esse local representado pela residência do sujeito, com ações mais práticas e pontuais, ou mesmo em um sentido mais amplo de espaço e estratégias. Neste caso, pode ser o bairro ou o município como um todo, com ações que levem à transformação da relação social em todos os níveis, mobilizando todos para a construção de um propósito coletivo de mudança da realidade local (MONTENEGRO-GÓMEZ, 2002).

Ressalta-se que as ações de EA para o desenvolvimento local podem ser desempenhadas por líderes e/ou associações comunitárias que exerceriam, assim, o papel do educador social, já que podem articular ações para transformação socioambiental e de desenvolvimento do território.

\section{CONSIDERAÇÕES FINAIS}

Diante do exposto, é necessário averiguar o que os programas de Educação Ambiental têm proporcionado para a sociedade. Deve-se analisar se eles têm sido desenvolvido sem uma perspectiva conservadora ou crítica da Educação Ambiental e se essas ações são passivas de promover mudanças na realidade local,bem como onde são aplicadas ou executadas, a fim de se constatar de a Educação Ambiental atua como uma atividade propulsora de desenvolvimento local.Como a Educação Ambiental almeja promover mudanças nas relações socioambientais, pressupõe-se que o cidadão reflita sobre sua relação com o meio, sempre reformulando sua prática e estando atento ao contexto cultural, social e econômico.

A Educação Ambiental não pode ser vista como um trabalho de reprodução ideológica e estática por parte dos sujeitos que fazem parte do processo sensibilizador ou mesmo por aqueles que trabalham nesse campo, pois vivemos em um mundo no qual as ações e os acontecimentos constantemente interferem no processo social e ambiental do planeta.

Assim, é preciso que um programa de EA, ao ser desenvolvido, tenha essa visão conceitual e que, além disso, analise a identidade dos seus sujeitos para motivar a participação e a colaboração e, consequentemente, proporcione o desenvolvimento local nesses espaços onde a EA se faz presente. As práticas de EA não podem ser desenvolvidas sem avaliar as questões culturais, sociais, econômicas e políticas, algo que muitas vezes não é observado pelos propositores dos projetos ambientais.

No entanto, diante da carência do processo de inclusão da temática ambiental nos diversos currículos de formação, a introdução do sentido da EA corre o risco de ficar comprometida e, consequentemente, interferir no proces- 
so sensibilizador do trabalho ambiental. Uma das soluções para mitigar os diversos problemas que envolvem o campo da EA seria, de fato, o atendimento das recomendações do PNEA, principalmente a inserção da temática nos diversos currículos educacionais.

Dessa forma, o trabalho de EA deixaria de ter aquela ideia que trabalha somente o verde, como é defendida por alguns sujeitos, mas se constituiria como uma ação mais complexa e transformadora. Talvez assim os educadores ambientais deixassem de ser chamados de "ecochatos", passando a ser reconhecidos pelo seu trabalho socioambiental. No que cabe ao educador social, este também merece ser reconhecido, já que ele se aproxima do educador ambiental. Finalmente, ressalta-se o fato de que a EA não é um trabalho somente dos educadores da educação formal e que os educadores sociais são, em muitas situações, os principais promotores da EA em diversos espaços e projetos desenvolvidos fora do espaço escolar.

Para trabalhos futuros, sugere-se uma investigação em torno dessa temática sobre quais profissionais estão aptos a serem reconhecidos como educadores ambientais. Dito de outra forma, é preciso averiguar quais atribuições devem ser levadas em consideração para denominar um profissional como educador ambiental, principalmente nos espaços nãoformais, tendo em vista que a EA formal é uma temática transversal e interdisciplinar.

\section{REFERÊNCIAS}

ABREU, Daniela Gonçalves; MOURA, Manoel Oriosvaldo. Construção de instrumentos teórico-metodológicos para captar a formação de professores. Educ Pesqui, São Paulo, v. 40, n. 2, p. 401-414, out. 2013. Disponível em: <http:// www.scielo.br/pdf/ep/2013nahead/aop1188.pdf >. Acesso em: 19 out. 2016.

ALBAGLI, Sarita. Globalização e espacialidade: o novo papel do local. In: CASSIOLATO, José Eduardo (Org.). Globalização e inovação localizada: experiências de sistemas locais no Mercosul. Rio de Janeiro: Redesist/UFRJ, 1998. p. 181-198. Disponível em: <http://www.redesist. ie.ufrj.br/nts/nt1/NTo4.PDF >. Acesso em: 19 mar. 2015.

ALBANUS, Lívia Lucina Ferreira; ZOUVI, Cristiane Lengler. Ecopedagogia: educação e meio ambiente. Curitiba: Intersaberes, 2013. (Série Pedagogia Contemporânea).

ARAÚJO, Joselaine; LUVIZOTTO, Caroline Kraus. Educação não formal: a importância do educador social na construção de saberes para a vida em coletividade. Colloquium Humanarum, Presidente Prudente, v. 9, n. 2, p. 73-78, jul./dez. 2012. Disponível em: <http://revistas.unoeste. $\mathrm{br} / \mathrm{revistas} / \mathrm{ojs} /$ index.php/ch/article/view/818/839>. Acesso em: 26 fev. 2016. 
AZEVEDO, Maria Antonia Ramos; ANDRADE Maria de Fátima Ramos. O conhecimento em sala de aula: a organização do ensino numa perspectiva interdisciplinar. Educar, UFPR, Curitiba, n. 30, p. 235-250, 2007.

BELO HORIZONTE. Prefeitura. Secretaria Municipal Adjunta de Meio Ambiente. Relatório Final do XXXI BH Itinerante: curso de extensão em Educação Ambiental. Projeto Sala Verde - Centro de Extensão em Educação Ambiental. Belo Horizonte/MG, janeiro 2016.

BELO HORIZONTE. Prefeitura. Secretaria Municipal de Meio Ambiente. Projeto Sala Verde: Centro de Extensão em Educação Ambiental.Belo Horizonte/MG, abril 2005.

BRASIL. Ministério do Meio Ambiente Lei no 6.938, de 31 de agosto de 1981. Dispõe sobre a Política Nacional do Meio Ambiente, seus fins e mecanismos de formulação e aplicação, e dá outras providências. Diário Oficial da República Federativa do Brasil, Brasília, DF, 31 ago. 1981. Disponível em: <http://www.planalto.gov.br/ccivil_03/LEIS/L6938.htm>. Acesso em: 25 ago. 2015.

BRASIL. Constituição (1988). Constituição da República Federativa do Brasil. Brasília, DF: Senado Federal, 1988.

BRASIL. Ministério do Meio Ambiente. Lei no 9.795, de 27 de abril de 1999.

Regulamenta a Lei no 9.795, de 27 de abril de 1999, que institui a Política Nacional de Educação Ambiental, e dá outras providências. Diário Oficial da República Federativa do Brasil, Brasília, DF, 21 abr. 1999. Disponível em: <http://www.planalto.gov.br/ccivil_03/decreto/2002/d4281.htm>. Acesso em: 22 nov. 2015.

BRASIL. Ministério do Meio Ambiente. Decreto 4.281, de 25 de junho de 2002. Regulamenta a Lei $\mathrm{n}^{\circ}$ 9.795, de 27 de abril de 1999, que institui a Política Nacional de Educação Ambiental, e dá outras providências. Diário Oficial da República Federativa do Brasil, Brasília, DF, 26 jun. 2002. Disponível em: <http://www.planalto.gov.br/ccivil_03/decreto/2002/d4281.htm>. Acesso em: 22 nov. 2015.

BRASIL. Ministério do Meio Ambiente. Ministério da Educação. Programa Nacional de Educação Ambiental. 3. ed. Brasília: MMA; MEC, 2005.

BRASIL. Ministério do Meio Ambiente. Lei no 12.305, de 2 de agosto de 2010. Institui a Política Nacional de Resíduos Sólidos; altera a Lei $\mathrm{n}^{\circ}$ 9.605, de 12 de fevereiro de 1998; e dá outras providências. Diário Oficial da República Federativa do Brasil, Brasília, DF, 2 ago. 2010. Disponível em: <http://www.planalto.gov.br/ccivil_03/_ato20072010/2010/lei/l12305.htm>. Acesso em: 25 ago. 2015. 
BRASIL. Ministério do Meio Ambiente. Ministério da Educação. Programa Nacional de Educação Ambiental. 4. ed. Brasília: MMA; MEC, 2014.

BRASIL. Ministério do Meio Ambiente. Agenda 21 Global. 2015a. Disponível em: <http://www.mma.gov.br/ responsabilidade-socioambiental/agenda-21/agenda-21-global>. Acesso em: 6 out. 2015a.

BRASIL. Ministério do Meio Ambiente. Projetos Salas Verdes. 2015b. Disponível em: <http://www.mma. gov.br/educacao-ambiental/educomunicacao/salas-verdes\#oprojeto>. Acesso em: 6 out. 2015.

BRÜGGER, Paula. Educação ou adestramento ambiental. 3. ed. rev. e ampl. Chapecó: Argos; Florianópolis: Letras Contemporâneas, 2004.

CONAMA. Conselho Nacional do Meio Ambiente. Recomendação $n^{0}$ 11, de 04 de maio de 2011. Recomenda diretrizes para a implantação, funcionamento e melhoria da organização dos Centros de Educação Ambiental - CEA, e dá outras orientações. Disponível em: <http://www.mma. gov.br/port/conama/recomen/recomen11/recom112011. pdf $>$. Acesso em: 25 nov. 2016.

DIAS, Genebaldo Freire. Educação ambiental: princípios e práticas. 9. ed. São Paulo: Gaia, 2004.

FRAGOSO, António. Contributos para o debate teórico sobre o desenvolvimento local: um ensaio baseado em experiências investigativas. Revista Lusófona de Educação, n. 5, p. 63-83, 2005. Disponível em: <http://www. scielo.gpeari.mctes.pt/pdf/rle/n5/n5a04.pdf >. Acesso em: 27 mar. 2015.

FREIRE, Paulo. Pedagogia da autonomia: saberes necessários à prática educativa. 25. ed. São Paulo: Paz e Terra, 1996.

GADOTTI, Moacir. Significado e desafio da educação básica. International Workshop - World University Service (WUS). Education for all: a challenge for democracy and human rights. NEW DELHI - INDIA, 6-8 sep. 1991. Disponível em: <http://siteantigo.paulofreire.org/pub/ Institucional/MoacirGadottiArtigosIto018/Significado_ Desafio_1991.pdf>. Acesso em: 11 set. 2014.

GADOTTI, Moacir. Perspectivas atuais da educação. Porto Alegre: Artes Médicas, 2000. Disponível em: <http://www.scielo.br/pdf/spp/v14n2/9782.pdf>. Acesso em: 2 set. 2014 .

GERRA, Antônio Fernando S.; ORSI, Raquel Fabiane Mafra. Tendências, abordagens e caminhos trilhados no 
processo de formação continuada em Educação Ambiental. REMEA- Revista Eletrônica do Mestrado de Educação Ambiental,v. especial, p. 28-45, dez. 2013. Disponível em: <https://www.seer.furg.br/remea/article/ view/3386/2032>. Acesso em: 21 out. 2016.

GIARETTA, Juliana Barbosa Zuquer; FERNANDES, Valdir; PHILIPPI JR., Arlindo. Desafios e condicionantes da participação social na gestão ambiental municipal no Brasil. Organ. Soc., Salvador, v. 19, n. 62, p. 527-550, set. 2012. Disponível em: <http://www.scielo.br/pdf/osoc/ v19n62/o9.pdf>. Acesso em: 14 out. 2015.

GOHN, Maria da Glória. Educação não formal, participação da sociedade civil e estruturas colegiadas nas escolas. Ensaio: aval pol. públ. educ., Rio de Janeiro, v. 14, n. 50, p. 27-38, jan./mar. 2006. Disponível em: <http://www. scielo.br/pdf/ensaio/v14n5o/30405>. Acesso em: 17 out. 2016.

GOHN, Maria da Glória. Educação não formal, educador(a) social e projetos sociais de inclusão. Meta: avaliação, Rio de Janeiro, v. 1, n. 1, p. 28-43, 2009. Disponível em: $<$ http://revistas.cesgranrio.org.br/index.php/metaavaliacao/article/view/1>. Acesso em: 22 nov. 2015.

GUIMARÃES, Mauro. A dimensão ambiental na educação. 11. ed. Campinas: Papirus, 2013.

JACOBI, Pedro Roberto.Educação ambiental, cidadania e sustentabilidade. Cad Pesqui, São Paulo, n. 118, p. 189-206, março de 2003.Disponível em: <http://www. scielo.br/scielo.php?script $=$ sci_arttext\&pid $=$ So10o$-15742003000100008 \& \operatorname{lng}=\mathrm{en} \& \mathrm{nrm}=\mathrm{iso}>$. Acesso em: 28 de nov. 2016.

JACOBI, Pedro Roberto; TRISTÃO, Martha; FRANCO, Maria Isabel Gonçalves Correa. A função social da Educação Ambiental nas práticas colaborativas: participação e engajamento. Cadernos Cedes, Campinas, v. 29, n. 77, p. 63-79, jan./abr. 2009.

KAWASAKI, Clarice Sumi; MATOS, Mauricio dos Santos; MOTOKANE, Marcelo Tadeu. O perfil do pesquisador em Educação Ambiental: elementos para um estudo sobre a constituição de um campo de pesquisa em Educação Ambiental. Pesquisa em Educação Ambiental, [S.l.], v. 1, n. 1, p. 111-140, jul. 2006. Disponível em: <http:// www.periodicos.rc.biblioteca.unesp.br/index.php/pesquisa/article/view/6118>. Acesso em: 24 out. 2016.

LAYRARGUES, Philippe Pomier. A crise ambiental e suas implicações na educação: pensando e praticando Educação Ambiental na gestão do meio ambiente. 2. ed., Brasília: IBAMA, 2002. Disponível em: <http://www. 
educacaoambiental.pro.br/victor/ biblioteca/ LayrarguesCriseAmb.pdf>. Acesso em: 18 out. 2016.

LAYRARGUES, Philippe Pomier; LIMA, Gustavo Ferreira da Costa. Mapeando as macrotendências político-pedagógicas da Educação Ambiental contemporânea no Brasil. In: Encontro Pesquisa em Educação Ambiental, v. 7, 2011. Disponível em: <http://www.icmbio.gov.br/educacaoambiental/images/stories/biblioteca/educacao_ambiental/Layrargues_e_Lima_-_Mapeando_as_macro-tend\%C3\%AAncias_da_EA.pdf>. Acesso em: 24 out. 2016.

LIBÂNEO, José Carlos. Os significados da educação, modalidades de prática educativa e a organização do sistema educacional. In: LIBÂNEO, José C. Pedagogia e pedagogos, para quê? São Paulo, Cortez, 1998. p. ?

LIMA, Maria José Araújo. Ecologia humana: realidade e pesquisa. Petrópolis: Vozes, 1984.

LONGO, Gabriela Rodrigues. Educação Ambiental e educação em valores na formação de professores. REMEARevista Eletrônica do Mestrado em Educação Ambiental, [S.l.], v. 33, n. 1, p. 256-268, maio 2016. ISSN 1517-1256. Disponível em: <https://www.seer.furg.br/remea/article/view/5624>. Acesso em: 1 nov. 2016.

MACHADO, Evelcy Monteiro. Pedagogia social no Brasil: políticas, teorias e práticas em construção. Curitiba: UFPR(2009). Disponível em: < http://sites.unicentro.br/ wp/cursodepedagogia/files/2011/o8/artigo_-Pedagogia_ Social1-Evelcy.pdf>. Acesso em: 28 nov. 2015.

MARTINS, Rafael D’Almeida; VAZ, José Carlos;CALDAS, Eduardo de Lima.A gestão do desenvolvimento local no Brasil: (des)articulação de atores, instrumentos e território.Rev. Adm. Pública, Rio de Janeiro, v. 44, n.3, p.559-590, jun. 2010. Disponível em: <http://www.scielo.br/scielo.php?script=sci_arttext\&pid=So034-7612201 ooo0300002\&lng=en\&nrm=iso $>$.Acesso em: 29 nov. 2016.

MINAS GERAIS. Fundação Estadual do Meio Ambiente. Termo de referência para Educação Ambiental não formal no processo de licenciamento ambiental do Estado de Minas Gerais. 2015. Disponível em: <http:// www.meioambiente.mg.gov.br/regularizacao-ambiental/ termos-de-referencia>. Acesso em: 28 nov. 2015.

MONTENEGRO-GÓMEZ, Jorge. Crítica ao conceito de desenvolvimento. Pegada Eletrônica, Presidente Prudente, v. 3, n. 1, p. 20-32, 2002. Disponível em: <http:// revista.fct.unesp.br/index.php/pegada/article/viewFile/798/821>. Acesso em: 1 nov. 2015. 
MORIN, Edgar. Ciência com consciência. 9. ed., capítulo 6-1 ${ }^{\text {a }}$. parte. Rio de Janeiro: Bertrand Brasil, 2005.

NUNES, Marcela Riccomi; PHILIPPI JR, Arlindo; FERNANDES, Valdir. A atuação de conselhos do meio ambiente na gestão ambiental local. Saúde Soc., São Paulo, v. 21, supl. 3, p. 48-6o, dez. 2012. Disponível em: <http://www.scielo.br/ scielo.php?script $=$ sci_arttext\&pid $=$ So10412902012000700 o05\&lng=en\&nrm=iso $>$. Acesso em: 22 nov. 2015.

PEQUENO, Maria Gorete Cavalcante; SILVA, Maria Eleni Henrique; COSTA, Lucinete Gadelha. Formação docente: desafios, propostas e perspectivas. In:ENCONTRO NACIONAL DE DIDÁTICA E PRÁTICA DE ENSINO - ENDIPE, 15., 2010. Belo Horizonte. Anais... Belo Horizonte: UFMG, 2010. 1 CD-ROM.

PEQUENO, Maria Gorete Cavalcante. Formação docente e Educação Ambiental: por uma Pedagogia do cuidado. REMEA - Revista Eletrônica do Mestrado em Educação Ambiental, v. 33, n. 1, p. 213-232, 2016. Disponível em: <https://www.seer.furg.br/ remea/article/view/5428/3604>. Acesso em: 20 out. 2016.

PINEL, Hiran; COLODETE, Paulo Roque; PAIVA, Jacyara Silva. Pedagogia social: definições, formação, espaços de trabalho, grandes nomes e epistemologias. Conhecimento em Destaque, Serra, v. 1, n. 2, jul./dez. 2012. Disponível em: <http://soufabra.com.br/revista/index.php/ cedfabra/article/view/11/3>. Acesso em: 22 nov. 2015.

POMBO, Olga. Práticas interdisciplinares. Sociologias, Porto Alegre, ano 8, n. 15, p. 208-249, jan./jun. 2006.

REIGOTA, Marcos. Desafios à Educação Ambiental escolar. In: In: CASCINO, Fábio; JACOBI, Pedro; OLIVEIRA, José Flávio de (Org.). Educação, meio ambiente e cidadania: reflexões e experiências. São Paulo: SMA, 1998. p. 43-50.

SATO, Michèle. Debatendo os desafios da Educação Ambiental. In:CONGRESSO DE EDUCAÇÃO AMBIENTAL PRÓ MAR DE DENTRO - FURG \& Pró Mar de Dentro, 1.,Rio Grande. Anais..., 17-21 maio 2001. Disponível em: <http://www.cpd1.ufmt.br/gpea/pub/DesafiosEA.pdf>. Acesso em: 5 set. 2014.

SAUVÉ, Lucie. Uma cartografia das correntes em Educação Ambiental. Educação Ambiental: Pesquisa e Desafios, p. 17-45, 2005. Disponível em: <http://web.unifoa.edu.br/portal_ensino/mestrado/mecsma/arquivos/ sauve-l.pdf $>$. Acesso em: 25 out. 2016.

SGARBI, Antonio Donizetti; LOBINO, Maria das Graças Ferreira; PINTO, Sabrine Lino; LOVAT, Therezinha de 
Jesus Chanca; MARQUES, Maria Luiza de Lima; SANTOS, Wellington Alves dos. A alfabetização científica no contexto da sustentabilidade: discussão sobre uma formação de agentes socioambientais. RevistaPráxis, v. 7, n. 14, 2016. Disponível em: <http://web.unifoa.edu.br/praxis/ojs/index. php/ praxis/article/view/282>. Acesso em: 21 out. 2016.

TENÓRIO; Fernando Guilherme; DUTRA, José Luís de Abreu; MAGALHÃES, Carla Marisa Rebelo de. Gestão social e desenvolvimento local: uma perspectiva a partir da cidadania deliberativa.In:ENCONTRO ANUAL DA ANPAD, v. 28, 2004. Anais...? 2004.p.?

THIESEN, Juares da Silva. A interdisciplinaridade como um movimento articulador no processo ensino-aprendizagem. Revista Brasileira de Educação, v. 13, n. 39, p. 545-554, set./dez. 2008.

TORO, José Bernardo; WERNECK, Nisia Maria. Mobilização social: um modo de construir a democracia e a participação. Bogotá: Fundación Bogotá, 1996.

Recebido em: 00/00/2017 Aprovado em: 00/00/2017 